\title{
PEROVSKITE-LIKE CATALYSTS FOR THE CATALYTIC FLAMELESS COMBUSTION OF METHANE
}

\author{
O. Buchneva ${ }^{a}$, I. Rossettia ${ }^{*}$, A. Kryukov ${ }^{b}$ \\ a) Dip. Chimica Fisica ed Elettrochimica, Università di Milano, v. C. Golgi, 19, \\ 20133 Milano, Italy \\ b) D.I.Mendeleev University of Chemical Technology of Russia, Miusskaya sq. 9. \\ 125047, Moscow, Russia
}

\section{QUESTIONNAIRE}

The catalytic flameless combustion (CFC) of methane outperforms conventional flame combustion because of lower emission of pollutants (HC, $\mathrm{CO}$ and $\mathrm{NO}_{\mathrm{x}}$ ) and high thermal efficiency. The catalysts traditionally used for CFC are mainly based on supported noble metals, such as Pd and Pt, which ensure high activity, however accompanied by some drawbacks, due to high cost and poor thermal and chemical stability. La-based catalysts with $\mathrm{ABO}_{3}$ perovskite-like structure have been proposed as a valid alternative for the present application. Indeed, perovskite catalysts combine low cost, thermochemical stability at high operating temperature and satisfactory catalytic activity. In spite of this, there are still some open questions, especially regarding their resistance to sulphur poisoning when used for the CFC of methane. Indeed, the poisoning mechanism of perovskite-like catalysts has not been completely understood and only a few papers deal with this very important topic.

In general, the partial substitution of the perovskitic lattice metal ions is one of the important means to modulate catalytic activity. In $\mathrm{LaBO}_{3}$ perovskites, the influence of dopants such as $\mathrm{A}^{, 2+}$ and $\mathrm{A}^{, 4+}$ has been widely investigated in the literature.

\footnotetext{
*Corresponding author: fax +39-02-50314300; e-mail ilenia.rossetti@unimi.it
} 
In the recent past, attention has been devoted to catalyst nanostructuring, aiming at obtaining high surface area and defectivity, which should enhance oxygen mobility through the lattice and ensure good catalytic activity. To this purpose, we set up and optimised a flame-pyrolysis (FP) apparatus for the onestep synthesis of perovskitic mixed oxides. It is based on a specially designed burner fed with oxygen and an organic solution of the precursors, the solvent acting as fuel for the flame. FP-synthesized perovskites, showed good phase purity, along with nanometer-size particles and hence very high surface area (sometimes in excess of $100 \mathrm{~m}^{2} / \mathrm{g}$ ). In addition, the high temperature of the flame in principle should also ensure thermal stability.

In the present work we prepared a set of samples by FP, namely $\mathrm{La}_{1-}$ ${ }_{x} \mathrm{~A}_{\mathrm{x}} \mathrm{MeO}_{3}$, with $\mathrm{A}^{\prime}=\mathrm{Ce}, \mathrm{Sr}, \mathrm{Ag} \mathrm{Me}=\mathrm{Mn}, \mathrm{Co}, \mathrm{x}=0,0.1,0.2$, either pure or doped with noble metals ( $\mathrm{Pt}, \mathrm{Pd}$ or $\mathrm{Ag}$ ). In addition silver containing samples were synthesized by a traditional sol-gel (SG) method. The catalysts were tested for the CFC of methane, monitoring the activity by online mass spectrometry. Also the resistance to sulphur poisoning was investigated, using tetrahydrothiophene as poisoning agent.

\section{INTRODUCTION}

La-based catalysts with $\mathrm{ABO}_{3}$ perovskite-like structure [1-4] have been proposed as a valid alternative for the low temperature catalytic flameless combustion of methane (CFC). Indeed, perovskite catalysts combine low cost, thermo-chemical stability at high operating temperature and satisfactory catalytic activity [5-8]. Interest is growing for these materials because of their interesting transport properties [9-20], such as oxygen mobility, important for their activity as catalysts in the catalytic flameless combustion of methane [1820] and for solid oxide fuel cells. Transport properties are strongly dependent on 
the nature of the ions partially substituting for $\mathrm{La}^{3+}$ [19] as well as on the preparation procedure [20].

A common way to tune catalytic activity is the partial substitution of one of the ions constituting the structure, which bring to different cell parameters of the perovskite lattice or the addition of a small amount of noble metals [21-23]. Furthermore, catalytic activity may be improved by the increase of specific surface area of catalysts.

One of the key problems dealing with catalytic conversion of natural gas is the presence of sulphur compounds, added as odorisers in the distribution grid, possibly leading to catalyst poisoning [24-26]. As all heterogeneous processes poisoning start from the adsorption of $\mathrm{SO}_{2}$ on the surface of the catalysts, which may simply block the active sites or modify their chemical nature. Indeed, once adsorbed, unstable $\mathrm{SO}_{2}$ surface species can react with activated oxygen, which leads to formation of different sulfur species $\left(\mathrm{SO}_{2}, \mathrm{SO}_{3}, \mathrm{SO}_{3}{ }^{2-}, \mathrm{SO}_{4}{ }^{2-}\right.$ and $\left.\mathrm{S}^{2-}\right)$ [1]. In addition, prolonged exposure to $\mathrm{SO}_{2}$ can lead to a complete destruction of the perovskite structure. Doping with noble metals or the introduction of transition metal ions forming unstable sulfates (e.g. Ti, $\mathrm{Zr}, \mathrm{V}, \mathrm{Sn}, \mathrm{Sr}, \mathrm{Ce}$ ) in catalyst formulation are possible means to improve the resistance to sulphur poisoning. Rosso et Al. [5, 27-28] also showed the beneficial role of $\mathrm{MgO}$, which acts as a protective shield, forming stable sulphates and hence competing with the active phase for $\mathrm{SO}_{2}$ adsorption. Its protective action is however provisional, due to its consumption. In a previous investigation [29] intra-framework Sr doping proved an interesting mean to improve catalyst resistance to poisoning, as well as the addition of noble metals, such as Pd or Pt. However, the former method showed beneficial for $\mathrm{LaMnO}_{3}$ based catalysts, whereas $\mathrm{LaCoO}_{3}$ showed decreasing activity upon $\mathrm{Sr}$ addition, besides being intrinsically less resistant to $\mathrm{S}$ poisoning.

In our work we summarise the results of different attempts to modify the perovskite structure to impart higher activity for the catalytic flameless 
combustion of methane and resistance to sulphur poisoning. For this purpose different series of catalysts were synthesized with schematic formula $\mathrm{La}_{1}$ ${ }_{x} \mathrm{~A}_{\mathrm{x}} \mathrm{MeO}_{3}$, were $\mathrm{A}=\mathrm{Sr}, \mathrm{Ce}, \mathrm{Ag} ; \mathrm{Me}=\mathrm{Co}, \mathrm{Mn} ; \mathrm{x}=0.05,0.1,0.2$. In addition, samples promoted with noble metals were prepared $\left(\mathrm{LaMeO}_{3}+0.5 \% \mathrm{NM}\right.$ were $\mathrm{Me}=\mathrm{Co}, \mathrm{Mn} ; \mathrm{NM}=\mathrm{Pt}, \mathrm{Pd}, \mathrm{Ag})$. Two preparation procedures have been followed: the traditional sol-gel method compared with flame pyrolysis (FP, [2-4]), leading to nanostructured catalysts.

\section{EXPERIMENTAL PART.}

\section{1 - Samples preparation}

Since only partial $\mathrm{Ag}$ incorporation in the $\mathrm{LaMeO}_{3}$ lattice can be reached (vide infra), the formula $\mathrm{La}_{1-\mathrm{x}} \mathrm{Ag}_{\mathrm{x}} \mathrm{MeO}_{3}$ should be better represented by $\mathrm{y}$ $\mathrm{Ag} / \mathrm{La}_{1-\mathrm{x}-\mathrm{y}} \mathrm{Ag}_{\mathrm{x}} \mathrm{MeO}_{3}$, where $x$ represents the fraction of $\mathrm{Ag}$ incorporated into the perovskite framework, whereas $y$ is the Ag molar fraction in extraframework position. However, to avoid complex notations, the nominal composition only will be used in the following.

\subsection{1 - Flame pyrolysis}

All the precursors solutions were prepared by dissolving in propionic acid (Aldrich, pur. 97\%) salts of the selected metals $\mathrm{La}\left(\mathrm{CH}_{3} \mathrm{COO}\right)_{3} \cdot 2 \mathrm{H}_{2} \mathrm{O}$ (Aldrich, pur. 99.9\%), $\mathrm{Co}\left(\mathrm{CH}_{3} \mathrm{COO}\right)_{2} \cdot 4 \mathrm{H}_{2} \mathrm{O}$ (Fluka, pur. 99\%), $\mathrm{Mn}\left(\mathrm{CH}_{3} \mathrm{COO}\right)_{2} \cdot 4 \mathrm{H}_{2} \mathrm{O}$ (Aldrich, pur. 99\%), $\mathrm{Sr}\left(\mathrm{CH}_{3} \mathrm{COO}\right)_{2}$ (Aldrich, pur. 99\%), $\mathrm{Ce}\left(\mathrm{CH}_{3} \mathrm{COO}\right)_{2}$ (Aldrich, pur. 99.9\%), $\mathrm{Pd}\left(\mathrm{CH}_{3} \mathrm{COO}\right)_{2}$ (Fluka, Pd 47wt\%), $\mathrm{Pt}(\mathrm{AcAc})_{2}$ (Aldrich, pur. 97\%), $\mathrm{Ag}\left(\mathrm{CH}_{3} \mathrm{COO}\right)$ in the desired ratio and metal concentration. The FP

apparatus has been described in detail elsewhere [30]. Briefly, it consists of a capillary tube (inner diameter $0.6 \mathrm{~mm}$ ) ending in the centre of a vertical nozzle 
and connected with a syringe pump (Harvard, mod. 975), feeding the solution of the mixed oxide precursors. The nozzle was co-fed with oxygen (SIAD, purity > 99.95\%, flow rate $5 \mathrm{~L} / \mathrm{min}$ ), acting both as oxidant and as dispersing agent, able to form micro-droplets of solution. Gas flow rate was regulated by MKS (mod. 1259C) mass flow meters, controlled by a MKS (mod. 247C) control unit. The synthesized nano-particles were collected by means of a $10 \mathrm{kV}$ electrostatic precipitator [31].

\subsection{2 - Sol-gel method}

Appropriate amounts of $\mathrm{La}\left(\mathrm{NO}_{3}\right)_{3} \cdot 6 \mathrm{H}_{2} \mathrm{O}$ (ChemSpectr, pur. >98\%), $\mathrm{Co}\left(\mathrm{NO}_{3}\right)_{2} \cdot 6 \mathrm{H}_{2} \mathrm{O}$ (Reachem, pur. >98\%), $\mathrm{Mn}\left(\mathrm{NO}_{3}\right)_{2} \cdot 6 \mathrm{H}_{2} \mathrm{O}$ (Reachem, pur. $>98 \%$ ) and $\mathrm{AgNO}_{3}$ (Reachem, pur. 99.95\%) were dissolved in distilled water. Citric acid (Reachem, pur. 99.9\%) was added to the solution as complexing agent with a 1.5:1 molar ratio with respect to the sum of metal cations. After evaporation of the solvent, a bulk powder was obtained, which was consecutively ignited at $300^{\circ} \mathrm{C}$ for $1 \mathrm{~h}$ and at $550^{\circ} \mathrm{C}$ and $700^{\circ} \mathrm{C}$ for $3 \mathrm{~h}$.

\section{2 - Catalyst characterization}

The crystal structure of the prepared samples was determined by X-ray powder diffractometry on a Philips PW3020 diffractometer operating with $\mathrm{Cu}$ $\mathrm{K}_{\alpha}$ radiation $(\lambda=1.5418 \AA)$. Patterns were collected in the range $5^{\circ} \leq 2 \theta \leq 80^{\circ}$ with $\Delta 2 \theta=0.02^{\circ}$ steps. The patterns obtained were compared with literature data for phase recognition [32]. The surface area of the synthesized powders was measured by $\mathrm{N}_{2}$ adsorption/desorption at $77 \mathrm{~K}$ on a Micromeritics ASAP2010 apparatus, after outgassing at $300^{\circ} \mathrm{C}$ overnight. Scanning electron miscoscopy (SEM) analysis was carried out on a LEICA LEO 1420 instrument.

Temperature programmed reduction (TPR) was carried out on ca. $0.15 \mathrm{~g}$ of catalyst, pretreated in $\mathrm{He}\left(40 \mathrm{~cm}^{3} / \mathrm{min}\right)$ from room temperature up to $800^{\circ} \mathrm{C}$ $\left(10^{\circ} \mathrm{C} / \mathrm{min}\right)$ and kept for $1 \mathrm{~h}$, then presaturated by oxygen in air flow at $750^{\circ} \mathrm{C}$ for 
1h, by flowing $40 \mathrm{~cm} 3 / \mathrm{min}$ of $10 \mathrm{vol} \% \mathrm{H}_{2}$ in He gas mixture and by increasing temperature from r.t. up to $800^{\circ} \mathrm{C}$ by $10^{\circ} \mathrm{C} / \mathrm{min}$. The analysis was accomplished by on line quadrupolar mass spectrometry, by using the same apparatus described for activity testing.

\section{3 - Catalytic activity testing}

Catalytic activity tests were carried out by means of a continuous quartz tubular reactor on $c a .0 .15 \mathrm{~g}$ of catalyst, pelletized, ground and sieved to 0.15 $0.25 \mathrm{~mm}$ particles. Prior to each run, the catalyst was activated in flowing air (20 $\mathrm{cm}^{3} / \mathrm{min}$ ), while increasing temperature by $10^{\circ} \mathrm{C} / \mathrm{min}$ up to $600^{\circ} \mathrm{C}$, then kept for $1 \mathrm{~h}$. The activity tests were carried out by feeding a mixture composed of 0.34 vol\% $\mathrm{CH}_{4}, 33.3$ vol\% air, He balance, while increasing temperature by $10^{\circ} \mathrm{C} / \mathrm{min}$ from $200^{\circ} \mathrm{C}$ up to $600^{\circ} \mathrm{C}$. Gas flow rate was regulated by means of mass flowmeters (Brooks Instruments, mod. 5850) governed by a control unit (Brooks, mod. 0154). The total gas flow rate was $30 \mathrm{ml} / \mathrm{min}$. The outcoming gas was analyzed in line by means of a quadrupolar mass spectrometer (MKS, PPT Residual Gas Analyzer), selecting proper mass fragments.

Catalyst poisoning tests were carried out in the same apparatus at $450^{\circ} \mathrm{C}$ by injecting 4 doses of $0.15 \mathrm{mg}$ of tetrahydrothiophene (THT, Fluka, pur. >97\%) per $1 \mathrm{~g}$ of catalyst, each group of four injections being defined as cycle (corresponding to $0.6 \mathrm{mg}$ THT per $\mathrm{g}$ of catalyst). The catalytic activity was monitored "in operando" during poisoning, by continuously analyzing the relevant mass fragments $\left(\mathrm{CH}_{4}, \mathrm{THT}, \mathrm{SO}_{2}, \mathrm{SO}_{3}, \mathrm{CO}, \mathrm{CO}_{2}, \mathrm{H}_{2} \mathrm{O}\right)$ and plotting them as partial pressure versus time. The data have been further elaborated by calculating the slope of some descriptive lines, indicating the transient response of the catalyst during poisoning, as better detailed in the following. The standard activity test was then repeated after each poisoning cycle. 


\section{RESULTS AND DISCUSSION}

\subsection{Catalysts characterization}

For the $\mathrm{Sr}$ - and Ce-containing catalysts, all the present samples were characterized by high phase purity, since no reflection of extraneous phases has been ever observed for the fresh samples. This indicates dopant incorporation into the framework or at least very high dispersion as small aggregates, whose size was lower than the detection limit of the XRD technique. Peak broadening has been observed for every sample due to the small particles size imparted by the FP preparation technique. Sometimes a bi-modal crystal-size distribution has been observed, i.e. fitting of the reflections described by two overlapping distributions. BET surface area ranged between $43 \mathrm{~m}^{2} / \mathrm{g}$ for $\mathrm{LaCoO}_{3}$ to $70 \mathrm{~m}^{2} / \mathrm{g}$ for $\mathrm{La}_{0.8} \mathrm{Sr}_{0.2} \mathrm{MnO}_{3}$, due to the flash calcination characterising the FP technique, which limits a deep sintering of the powder. No significant correlation was found between surface area and the nature, or the concentration of the various components. The particle size, determined by SEM analysis, was rather uniform and its mean value ranged between 20 and 50nm.

According to the XRD (Fig. 1) data for all the samples of the $\mathrm{La}_{1-\mathrm{x}} \mathrm{Ag}_{\mathrm{x}} \mathrm{CoO}_{3}$ series the main phase was the rhombohedral $\mathrm{LaCoO}_{3}$ (characterized by a double reflection at $2 \theta \approx 33^{\circ}$ ). Typically, the reflections of metallic silver were also observed $\left(2 \theta \approx 38.1^{\circ}, 44.6^{\circ}\right.$ and $\left.64.6^{\circ}\right)$, whose intensity increased with increasing Ag loading. This allowed to conclude a low Ag incorporation in the $\mathrm{LaCoO}_{3}$ framework $[33,34]$. Due to poor silver solubility, the lattice parameters of the host perovskite did not change dramatically, i.e. no relevant shift of the maximum reflection was observed for Ag-doped samples when compared with the undoped $\mathrm{LaCoO}_{3}$. Silver doping lead to opposite effects on surface area for SG and FP samples. For SG catalysts silver doping led to a slight decrease of 
specific surface area and increasing crystal size, likely due to silver segregation as separate phase.

For the $\mathrm{La}_{1-\mathrm{x}} \mathrm{Ag}_{\mathrm{x}} \mathrm{MnO}_{3}$ series a lower specific surface area was obtained with the SG-prepared catalysts than with the FP ones, silver doping increasing the surface area in all cases. However, also in this case no clear relationship between surface area and silver loading was drawn.

According to the XRD data for SG samples the main phase corresponds to rhombohedral (non-stoichiometric) $\mathrm{LaMnO}_{3+\delta}$, whereas for the FP samples the main phase corresponds to monoclinic $\mathrm{LaMnO}_{3}$. Reflections of metallic silver ( $2 \theta \approx 38.1^{\circ}, 44.6^{\circ}$ and $64.6^{\circ}$ were sometimes observed) for the doped samples, with increasing intensity at high Ag loading, in line with the much lower solubility of $\mathrm{Ag}$ in the $\mathrm{LaMnO}_{3}$ framework with respect to different dopants, such as $\mathrm{Sr}[33,34]$. The FP-prepared samples (Fig. 2) showed a small reflection of metallic silver even after 5\% Ag loading, whereas it was almost undetectable for the SG prepared ones. An evident broadening of Bragg's peaks was observed also in this case for the FP samples due to nanostructuring. Regrettably, it was impossible to ascertain whether or not $\mathrm{Ag}_{2} \mathrm{O}$ was present in the perovskitestructured samples, because the main $\operatorname{Ag}_{2} \mathrm{O}\left(\begin{array}{lll}1 & 1 & 1\end{array}\right)$ reflection $\left(2 \theta \approx 33^{\circ}\right)$ perfectly overlaps the main $\mathrm{LaMnO}_{3}$ phase.

\subsection{Catalytic activity}

All the catalysts exhibited a very high activity. Indeed, under the adopted reaction conditions full methane conversion was attained below $600^{\circ} \mathrm{C}$ and carbon dioxide + water were the only detected products. Mass spectrometric data showed sometimes a small drift of the baseline, which led to uncertain determination of $\mathrm{T}_{0}$, i.e. the temperature at which methane conversion started. Hence, the same activity tests were repeated while analysing the effluent gas by 
gas-chromatography, in order to check data accuracy. The results were comparable within $\pm 10^{\circ} \mathrm{C}$.

The activity data collected on fresh catalysts are presented in Tables 1 and 2. $\mathrm{T}_{50}$ was chosen as the main indicator of activity $\left(\mathrm{T}_{50}=\right.$ temperature at which $50 \%$ conversion of methane is achieved), the lower is this parameter, the higher is activity. At difference with what reported elsewhere [35], doping at A position for the FP samples did not bring about very significant effects on catalytic activity, i.e. $\mathrm{T}_{50}$ were similar for differently substituted samples, at least within the detection limits of the detection apparatus (vide supra). This is also due to the high catalytic activity of the whole set of samples, which flattens small differences in conversion.

$10 \% \mathrm{Sr}$ substitution moderately enhanced the activity of Mn-based perovskite and slightly decreased the activity of Co-based one. Further $\mathrm{Sr}$ addition in Mn-based perovskite did not show any positive effect on activity. By contrast, $\mathrm{Ce}^{4+}$-containing samples may show a $\mathrm{La}_{1-\mathrm{x}} \mathrm{Cey} \varnothing_{\mathrm{x}-\mathrm{y}} \mathrm{MeO}_{3}$ formula, $\varnothing$ being a cationic vacancy formed upon $\mathrm{CeO}_{2}$ segregation in extraframework position. In our Ce-substituted catalysts $\mathrm{y} \cong \mathrm{x}$, since the reflections of the $\mathrm{CeO}_{2}$ phase were never detected by XRD. In this case, $\mathrm{Ce}^{4+}$ in framework position can force an equivalent portion of the trivalent $\mathrm{B}$ metal ion to reduce to a formally divalent oxidation state. This usually stabilises the catalyst in reducing atmosphere and makes the formation of oxygen vacancies uneasy. However, Ce can act as oxygen buffer and its own $4+/ 3+$ redox cycle, occurring at temperature near to that of the $\mathrm{B}$ metal, can give a contribution to the whole catalytic reaction. By contrast, Sr-doping should lead to the increase of oxygen vacancies concentration, as well as to the increase of the B metal ion formal oxidation state, depending on its nature. The former effect is more likely with $\mathrm{B}=\mathrm{Co}$, though Nakamura et al. [36, 37] showed that in some cases oxygen vacancies did not form up to $\mathrm{x}=0.4$ with $\mathrm{B}=\mathrm{Mn}$. 
It was reported that catalytic activity of perovskites can be increased through the addition of small amounts of noble metals [23, 38, 39]. This is confirmed by the present data (Table 1) for Co-based perovskites doped with either Pt or Pd. By contrast, for Mn-based catalysts Pt doping led to an activity improvement, while Pd doping decreased methane conversion. Furthermore, as for undoped samples, catalytic activity for Mn-based perovskite was generally a bit higher than for the Co-based ones.

The total activity of silver containing series may be defined by the correlation of 4 factors[40]. Silver incorporation in framework position increases the concentration of lattice defects, which in turn affect oxygen mobility through the framework. This factor improves the intrafacial mechanism of the reaction and the catalytic activity. On the other hand, TPR data (Fig. 3) shown that the reduction temperature of $\mathrm{Co}^{3+}$ to $\mathrm{Co}^{2+}$, represented by the first TPR feature, increased of $c a .50^{\circ} \mathrm{C}$ with the FP-prepared $\mathrm{La}_{0.95} \mathrm{Ag}_{0.05} \mathrm{CoO}_{3-\delta}$ sample with respect to the undoped catalyst and of further $10^{\circ} \mathrm{C}$ for the $\mathrm{La}_{0.8} \mathrm{Ag}_{0.2} \mathrm{CoO}_{3-\delta} \mathrm{SG}$ catalyst, confirming a lower reducibility. It can be noticed the particular shoulder at $\mathrm{ca} .530^{\circ} \mathrm{C}$ for the latter sample, likely due to the reduction of $\mathrm{Ag}$ containing species and present only at high Ag loading. Thus framework silver decreases Co reducibility and lead to slower redox cycle, which in turn lead to a negative effect on activity.

Silver in extraframework position may also play two opposite roles. It was reported in literature [41-44] that silver particle larger then 5nm show catalytic activity for methane combustion by itself and thereby increase the total activity of the catalyst. By contrast, small silver particle would lead to too strong Ag-O bonds, so decreasing the number of active sites for methane oxidation under mild conditions [44]. This type of silver is catalytically inert and plays the role of inert additive thereby decrease the total activity of catalyst per mass of catalyst loaded. In all particular case one of these factors is prevailing and determines the activity of sample. 
Partial substitution of $\mathrm{Ag}$ for La led to moderate contribution to activity in the case of Co-based sol-gel samples, an evident improvement of conversion appearing only at low Ag-loading. By contrast, the FP samples showed an activity improvement only with $20 \mathrm{~mol} \% \mathrm{Ag}$ doping, lower silver addition inducing even negative effects on catalyst performance (Table 2). This can be explained considering the poor $\mathrm{Ag}$ incorporation in such samples leading to well dispersed extralattice small Ag particles.

For the Ag doped Mn-based catalysts, the activity of FP-prepared samples was always higher than that of SG-prepared ones with identical nominal composition (Table 2). At the contrary than for cobaltites, the partial substitution of Ag for La led to increasing activity both for SG- and FP-prepared Mn-based catalysts and the catalytic activity always increased with increasing $\mathrm{Ag}$ substitution. Another interesting difference with respect to $\mathrm{La}_{1-\mathrm{x}} \mathrm{Ag}_{\mathrm{x}} \mathrm{CoO}_{3}$ systems is that the partial substitution of $\mathrm{Ag}^{+}$for $\mathrm{La}^{3+}$ led to a decrease of the onset temperature of the first reduction peak and enlarged the reducibility range of $\mathrm{Mn}$ ions. Indeed, by comparing with Co-based catalysts, a higher solubility of $\mathrm{Ag}$ in the manganite framework can be deduced with respect to the cobaltite one, as supported by XRD data. This likely excludes or limits the catalytic effect of extraframework metallic Ag in the Mn-based catalysts. The attention must be then focused on the effect of lattice $\mathrm{Ag}^{+}$ions on $\mathrm{Mn}$ reducibility and oxygen mobility. The higher $\mathrm{Mn}^{4+}$ reducibility, witnessed by TPR analysis, improved catalytic activity and the growing $\mathrm{Mn}^{4+}$ reduction with higher $\mathrm{Ag}$ loading showed beneficial to oxygen mobility. This was particularly relevant for the nanosized FP samples, for which a short bulk to surface pathway for framework oxygen is present. The latter feature favours methane oxidation by increasing the availability of bulk oxygen and easing catalyst reoxidation in the second step of the Mars van Krevelen mechanism. 
Finally, it should be noticed that the present FP-prepared $\mathrm{La}_{0.9} \mathrm{Ag}_{0.1} \mathrm{MnO}_{3 \pm \delta}$ catalyst showed the most active among the wide series of cobaltite and manganese perovskites prepared and tested for this application.

\subsection{Resistance to sulphur poisoning}

Tetrahydrothiophene (THT) has been selected as poison due to its wide use as odorising agent in the methane distribution grid (where its concentration is ca. $8 \mathrm{ppmv}$ ). The common poison used in the literature for poisoning tests is $\mathrm{SO}_{2}$, because many papers dealing with this topic focus on catalytic mufflers, where exhaust combustion gases are the feeding mixture of the catalytic reactor (muffler). In the present case we concentrated on the use of odorised methane as feed for catalytic combustors and hence we took into consideration also the decomposition mechanism of the S-containing species under operating conditions as near as possible to the operating ones. It should be underlined that this is relevant not only to centralized power generation, but, most of all, to distributed micro-generation, where the natural gas grid provides the feed without the possibility of very efficient pretreatment. A preliminary set of experiments allowed concluding that THT instantly decomposed to $\mathrm{SO}_{2}, \mathrm{CO}_{2}$ and $\mathrm{H}_{2} \mathrm{O}$ in the presence of every catalyst at $450^{\circ} \mathrm{C}$. This temperature has been selected because most samples exhibit the highest reaction rate around this value and the conversion curve is very steep, so to magnify the effect of poisoning.

All samples lost part of their initial activity for methane combustion after poisoning (Table 1-2). However, the degree of activity loss varied considerably with composition. For the estimation of the resistance against poisoning we have chosen to compare methane conversion at $450^{\circ} \mathrm{C}$ for the fresh and poisoned samples.

Sr substitution improved the resistance to sulphur poisoning for both Coand Mn-based perovskites, the resistance increasing with increasing the substitution degree. Sr-doping may force the B site cation to its highest valence 
state and/or increase the number of oxygen ion vacancies, so increasing the mobility of lattice oxygen. The acid character of a metal ion increases with its oxidation state and therefore the $\mathrm{SO}_{2}$ bonding with the surface might be weakened. On the other hand, $\mathrm{Ce}^{4+}$-substitution showed a different effect. In the case of Co-based perovskites it led to improved resistance to poisoning, while the opposite effect was observed for Mn-containing perovskites. The addition of $\mathrm{Ce}^{+4}$ brings about a partial reduction of the $\mathrm{B}$ ion, i.e. to less acidic $\mathrm{B}$ ions.

Among the set of noble metal doped samples $0.5 \% \mathrm{Pt} / \mathrm{LaMnO}_{3}$ showed the highest resistance to sulphur poisoning. For Mn-based perovskites the resistance was higher than for the Co-based one, as observed for the non-substituted samples (Table 1). However, the most evident effect has been observed after the first poisoning injections, suggesting that noble metals protect the surface sites by reacting more promptly with sulphur [22], Pt doping being more effective than Pd.

For the $(\mathrm{La}, \mathrm{Ag}) \mathrm{CoO}_{3}$ series, sol-gel prepared samples seemed a bit more resistant to sulphur addition than the FP-synthesised ones. Indeed, when comparing the residual conversion at $450^{\circ} \mathrm{C}$ after THT injection, the SG samples lost in average one point $\%$ of conversion less than the FP samples (Table 2, column $\Delta \%$ ). The difference of conversion levels between the fresh and the poisoned samples increased with Ag loading, except for a minimum with $\mathrm{La}_{0.9} \mathrm{Ag}_{0.1} \mathrm{CoO}_{3}$ for both the FP and SG preparation methods (-10/11 points\%), up to 20 points $\%$ with the highest silver amount. The relatively lower impact of the poison on SG-prepared samples can be explained on the basis of their lower surface area.

For $(\mathrm{La}, \mathrm{Ag}) \mathrm{MnO}_{3}$ series silver substitution did not change appreciably the resistance to poisoning for the FP prepared samples (Table 2), methane conversion decreasing by $c a$. 8-9 points $\%$ as for the unsubstituted sample. On the other hand, a higher absolute drop of conversion was visible for the SGprepared Ag-doped samples with respect to the unsubstituted sample. 
Nevertheless, due to the very poor catalytic performance of sample SG$\mathrm{LaMnO}_{3}$, the residual activity after poisoning was less than $30 \%$ of the initial value (Table 2).

As already mentioned, silver doping changed the lattice parameters and the properties of the perovskite, but its effect on the resistance to sulphur poisoning is controversial. On one hand, the difference of valence state between $\mathrm{La}$ and $\mathrm{Ag}$ brings part of $\mathrm{Mn}^{3+}$ to a higher valence state, namely to $\mathrm{Mn}^{4+}$, which is more acidic with the consequence above stated. On the other hand, framework $\mathrm{Ag}^{+}$ substitution increases the amount of oxygen vacancies, as in the case of Cobased perovskites that in turn makes easier $\mathrm{SO}_{2}$ adsorption. It should be also mentioned that extraframework metallic silver may directly act as a sulphur guard by reacting more promptly with sulphur compounds than the main perovskitic phase. The latter effect showed less sensitive for the present catalysts with respect to the $(\mathrm{La}, \mathrm{Ag}) \mathrm{CoO}_{3}$ samples, due to the already mentioned higher solubility of Ag in the manganite structure than in the cobaltite one. However, it may explain why the FP-prepared samples showed much more resistant to sulphur poisoning than the SG ones.

For the SG-prepared samples with low Ag loading, in which silver was mainly in lattice position, the partial oxidation of $\mathrm{Mn}^{3+}$ to $\mathrm{Mn}^{4+}$ helped improving the resistance to poisoning. FP-prepared catalysts, even with a low substitution level, were characterised by a lower Ag incorporation into the lattice with respect to the SG samples, extraframework silver exploiting its beneficial effect as sulphur guard rather than as activity enhancer, since $\mathrm{Ag}^{0}$ particle size was too small from that point of view.

However, it should be underlined by looking at the present data that $\mathrm{Ag}$ showed less effective than $\mathrm{Sr}$ from the point of view of catalyst protection against poisoning. With the present Ag-doped samples the main advantage is the improved initial activity of some of them, which leads to satisfactory results even after more or less severe poisoning. Indeed, when the comparison between 
the activity on fresh and doped samples is carried out by considering the whole activity curve, one may observe that even after poisoning the FP prepared $\mathrm{La}_{0.8} \mathrm{Ag}_{0.2} \mathrm{CoO}_{3}$ sample showed satisfactory activity, e.g. lower than the undoped FP prepared $\mathrm{LaCoO}_{3}$, but higher than the SG prepared one, even when considering the fresh samples. Furthermore, the FP- $\mathrm{La}_{0.9} \mathrm{Ag}_{0.1} \mathrm{MnO}_{3}$ sample was still able to convert $75 \%$ of methane at $450^{\circ} \mathrm{C}$ after four poisoning cycles, a catalytic performance much better even than that of the fresh FP- $\mathrm{LaMnO}_{3}$ sample.

\section{CONCLUSIONS}

A set of doped $\mathrm{La}_{1-\mathrm{x}} \mathrm{A}_{\mathrm{x}} \mathrm{MeO}_{3}$ samples have been prepared by different preparation methods, namely sol-gel and flame pyrolysis, leading to variable surface area and crystal size. Some dopants, like $\mathrm{Sr}^{+2}$ and $\mathrm{Ce}^{+4}$, showed a good substitution degree for La into the perovskite lattice, while silver incorporation was generally poor. This possibly left extraframework metallic silver, showing its own catalytic activity provided that proper Ag crystal size was reached. However, silver solubility strongly depended on preparation procedure.

All the present perovskite-like catalysts prepared by FP showed good activity for the CFC of methane, the best results being achieved with silver doped Mn-based catalysts (namely $\mathrm{La}_{0.9} \mathrm{Ag}_{0.1} \mathrm{MnO}_{3 \pm \delta}$ ). Good results have been also obtained with $\mathrm{La}_{0.9} \mathrm{Sr}_{0.1} \mathrm{MnO}_{3}$ and by adding $0.5 \mathrm{wt} \%$ Pt to $\mathrm{LaMnO}_{3}$ or $\mathrm{LaCoO}_{3}$.

Upon sulphur doping, a more or less evident conversion decrease was always observed except upon doping of manganites with $\mathrm{Sr}^{+2}$. Also noble metals provide some protection, at least after addition of a small amount of sulphur. Silver is not very effective from the point of view of protection against poisoning, but initial improvement of activity leads to a satisfactory results even after poisoning. 


\section{REFERENCES}

1. Y. Zhu, R. Tan, J. Feng, S. Ji, L. Cao. Appl. Catal. A 209 (2001) 71

2. G.L. Chiarello, I. Rossetti, L. Forni. J. Catal. 236 (2005) 251

3. G.L. Chiarello, I. Rossetti, L. Forni, P. Lopinto, G. Migliavacca. Appl. Catal. B 72 (2007) 218

4. G.L. Chiarello, I. Rossetti, L. Forni, P. Lopinto, G. Migliavacca. Appl. Catal. B 72 (2007) 227

5. I. Rosso, G. Saracco, V. Specchia, E. Garrone. Appl. Catal D 40 (2003) 195

6. I. Rossetti, 1. Forni, Appl. Catal. B: Environmental, 33 (2001) 345

7. L. Fabbrini, I. Rossetti, L. Forni, Appl. Catal. B: Environmental, 63 (2006) 131

8. R. Leanza, I. Rossetti, L. Fabbrini, C. Oliva, L. Forni, Appl. Catal. B: Environmental, 28 (2000) 55

9. H. Chiba, M. Kikuchi, K. Kusaba, Y. Miraoka, Y. Syono. Solid State Commun. 99 (1966) 499

10. A. Urushibara, Y. Moritomo, T. Arima, A. Asamitsu, G. Kido, Y. Tokura. Phys. Rev. B 51 (1995) 14103

11.0Y. Tokura, A. Urushibara, Y. Moritomo, T. Arima, A. Asamitsu, G. Kido, N. Furukawa. J. Phys. Soc. Jpn 63 (1994) 3931

12. B. Doudin, J-Ph Ansermet. Europhys. News 28 (1997) 14

13. C.Rettori, D. Rao, J.Singley, D. Kidwell, S.B. Oseroff, M.T. Causa, J.J. Newmeier, K.J. McClellan, S-W. Cheong, S. Schultz. Phys. Rev. B 55 (1997) 3083

14. S.B. Oseroff, M. Torikachvili, J. Singley, S. Ali. Phys. Rev. B 1996 (53) 6521

15. M.S. Seehra, M.M. Ibrahim, V.S. Babu, G. Srinivasan. J. Phys. Condens. Matter 8 (1996) 11283

16. N. Furukawa. J. Phys. Soc. Jpn. 65 (1996) 1174 
17. G. Papavassiliou, M. Fardis, M. Milia, A. Simopoulos, G. Kallias, M. Pissas,

D. Niarchos, N. Ioannidis, C. Dimitropoulos, J. Dilinsek. Phys. Rev. B 55 (1997) 15000

18. A.Shengelaya, Guo-meng Zhao, H.Keller, K.A.Muller. Phys.Rev.Lett. 77 (1996) 5296

19. C. Oliva, L. Forni, P. Pasqualin, A. D’Ambrosio, A.V. Vishniakov. Phys. Chem. Chem. Phys. 1 (1999) 355

20. C. Oliva, L. Forni. Catalysis Commun. 1 (2000) 5

21. K.-S. Song, H.X. Cui, S.D. Kim, S.-K. Kang. Catal. Today. 1999 (47) 155

22. M.J. Koponen, T. Venäläinen, M. Suvanto, K. Kallinen, T-J.J. Kinnunen, M.

Härkönen, T.A. Pakkanen. J. Molec. Catal. A 258 (2006) 246

23. M.A. Peña, J.L.G. Fierro, Chem Rev. 101 (2001) 1981

24. R.J.H. Voorhoeve, L.E. Trimble, C.P. Khattak, Mat. Res. Bull., 9 (1974) 655

25. L. Wan, in "Properties and applications of the Perovskite-type oxides", G. Tejuca, J.L.G. Fierro (Eds.), Marcel Dekker, New York, 1993, 145

26. L.G. Tejuca, J.L.G Fierro, J.M.D Tascón, Advances in Catal., 36 (1989) 237

27. I. Rosso, E. Garrone, F. Geobaldo, B. Onida, G. Saracco, V. Specchia, Appl. Catal. B: Environmental, 34 (2001) 29

28. I. Rosso, E. Garrone, F. Geobaldo, B. Onida, G. Saracco, V. Specchia, Appl.

Catal. B: Environmental, 30 (2001) 61

29. I. Rossetti, O. Buchneva, C. Biffi, R. Rizza, Appl. Catal. B: Environmental, 89 (2009) 383

30. G.L. Chiarello, I. Rossetti, , P. Lopinto, G. Migliavacca, L. Forni, Catal. Today, 117 (2006) 549

31. R.A.M. Giacomuzzi, M. Portinari, I. Rossetti, L. Forni, Stud. Surf. Sci.

Catal., A. Corma, F.V. Melo, S. Mendioroz, J.L.G. Fierro (Eds), vol. 130, Elsevier, Amsterdam, 2000, 197

32. Selected Powder Diffraction Data, Miner. DBM (1-40), J.C.P.D.S., Swarthmore, PA, 1974-1992 
33. A. Machocki, T. Ioannides, B. Stasinska, W. Gac, G. Avgouropoulos, D. Delimaris, W. Grzegorczyk, S. Pasieczna. J. Catal., 227 (2004) 282

34. B. Kucharczyk, W. Tylus, Appl. Catal. A: General, 335 (2008) 28

35. R. Leanza, I. Rossetti, L. Fabbrini, C. Oliva, L. Forni, Appl. Catal. B: Environmental, 28 (2000) 55

36. T. Nakamura, M. Misono, Y. Yoneda, J. Catal. 83 (1983) 151

37. T. Nakamura, M. Misono, Y. Yoneda, Bull. Chem. Soc. Jpn 55 (1982) 394

38. H. Tanaka, M. Misono, Curr. Opin. Solid State Mater Sci 5 (2001)

39. M.J. Koponen, M. Suvanto, T.A. Pakkanen, K. Kallinen, T-J.J. Kinnunen, M. Härkönen, Solid State Sci 7 (2005) 7

40. O. Buchneva, I. Rossetti, C. Biffi, M. Allieta, A. Kryukov, N. Lebedeva, Appl. Catal. A 370 (2009) 24.

41. H.A. Engelhardt, D. Menzel, Surf. Sci., 57 (1976) 591.

42. K.C. Prince, A.M. Bradshaw, Surf. Sci. 126 (1983) 49

43. K.L. Anderson, J.K. Plischke, M.A. Vannice, J. Catal., 128 (1991) 148

44. L. Kundakovic, M. Flytzani-Stephanopoulos, Appl. Catal. A: General, 183 (1999) 35 


\section{Tables}

Table 1: Activity data of fresh and poisoned $\mathrm{La}_{1-x} \mathrm{~A}_{\mathrm{x}} \mathrm{MeO}_{3}$ and $\mathrm{LaMeO}_{3}+0.5 \% \mathrm{NM}$ catalysts (after 4 poisoning cycles, if not specified differently). $\mathrm{T}_{50}=$ temperature of $50 \% \mathrm{CH}_{4}$ conversion; $\operatorname{Conv}_{450^{\circ}} \mathrm{C}=\mathrm{CH}_{4} \%$ conversion at $450^{\circ} \mathrm{C}$. Activity data for poisoned samples given as residual $\mathrm{CH}_{4}$ $\%$ conversion at $450^{\circ} \mathrm{C} . \Delta=$ activity loss due to poisoning (conversion of fresh sample - residual conversion after the last poisoning cycle) expressed in points $\%$.

* - after 5 cycles

** - after 6 cycles

$* * *$ - after 9 cycles

\begin{tabular}{|c|c|c|c|c|c|}
\hline \multirow[b]{2}{*}{ Sample } & \multicolumn{2}{|c|}{ Fresh catalyst } & \multicolumn{2}{|c|}{ Poisoned catalyst } & \multirow[t]{2}{*}{$\Delta, \%$} \\
\hline & $\mathrm{T}_{50}$ & $\begin{array}{c}\text { Conv }_{45} \\
0^{\circ} \mathrm{C}\end{array}$ & 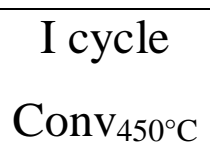 & $\begin{array}{l}\text { Last cycle } \\
\operatorname{Conv}_{450^{\circ} \mathrm{C}}\end{array}$ & \\
\hline $\mathrm{LaCoO}_{3}$ & 449 & 52.3 & 43.0 & 35.7 & 16.6 \\
\hline $\mathrm{La}_{0.9} \mathrm{Sr}_{0.1} \mathrm{CoO}_{3}$ & 453 & 48 & 46.6 & $44.2 *$ & $3.78^{*}$ \\
\hline $\mathrm{La}_{0.9} \mathrm{Ce}_{0.1} \mathrm{CoO}_{3}$ & 447 & 52.5 & 53 & 44.4 & 8.2 \\
\hline $\mathrm{LaMnO}_{3}$ & 435 & 59.4 & 54.1 & 49.9 & 9.5 \\
\hline $\mathrm{La}_{0.9} \mathrm{Ce}_{0.1} \mathrm{MnO}_{3}$ & 433 & 59.5 & 55.5 & 45.7 & 13.8 \\
\hline $\mathrm{La}_{0.9} \mathrm{Sr}_{0.1} \mathrm{MnO}_{3}$ & 419 & 70 & 66.5 & $63.6 * *$ & $6.8 * * *$ \\
\hline $\mathrm{La}_{0.8} \mathrm{Sr}_{0.2} \mathrm{MnO}_{3}$ & 434 & 60 & 57.4 & $53.7 * *$ & $6.3 * * *$ \\
\hline $0.5 \% \mathrm{Pt}+\mathrm{LaCoO}_{3}$ & 435 & 60.4 & 52.25 & 40.3 & 20.1 \\
\hline $0.5 \% \mathrm{Pt}+\mathrm{LaMnO}_{3}$ & 426 & 64.55 & 67.1 & 55 & 9.55 \\
\hline $0.5 \% \mathrm{Pd}+\mathrm{LaCoO}_{3}$ & 441 & 56.7 & 52.6 & 35.4 & 21.3 \\
\hline $0.5 \% \mathrm{Pd}+\mathrm{LaMnO}_{3}$ & 445 & 53 & 50 & 41.5 & 11.5 \\
\hline
\end{tabular}


Table 2: Activity data of fresh and poisoned (4 cycles) $\mathrm{La}_{1-\mathrm{x}} \mathrm{Ag}_{\mathrm{x}} \mathrm{MeO}_{3} . \mathrm{T}_{50}=$ temperature of $50 \% \mathrm{CH}_{4}$ conversion; $\mathrm{Conv}_{450^{\circ} \mathrm{C}}=\mathrm{CH}_{4} \%$ conversion at $450^{\circ} \mathrm{C}$. Activity data for poisoned samples given as residual $\mathrm{CH}_{4} \%$ conversion at $450^{\circ} \mathrm{C} . \Delta=$ activity loss due to poisoning (conversion of fresh sample - residual conversion after the last poisoning cycle) expressed in points $\%$.

\begin{tabular}{|c|c|c|c|c|c|c|}
\hline \multirow[t]{2}{*}{ Sample } & \multirow[t]{2}{*}{ Method } & \multicolumn{2}{|c|}{ Fresh catalyst } & \multicolumn{2}{|c|}{ Poisoned catalyst } & \multirow[b]{2}{*}{$\Delta, \%$} \\
\hline & & $\mathrm{T}_{50}$ & $\begin{array}{c}\text { Conv }_{450} \\
\%\end{array}$ & $\begin{array}{c}\text { I cycle } \\
\text { conv }_{450}, \%\end{array}$ & $\begin{array}{l}\text { Last cycle, } \\
\text { conv }_{450}, \%\end{array}$ & \\
\hline $\mathrm{LaCoO}_{3}$ & FP & 450 & 50 & 43.0 & 35.7 & 14.3 \\
\hline $\mathrm{LaCoO}_{3}$ & SG & 490 & 30 & 22.9 & 17.5 & 12.5 \\
\hline $\mathrm{La}_{0.95} \mathrm{Ag}_{0.05} \mathrm{CoO}_{3}$ & FP & 457 & 44.5 & 32.3 & 29.1 & 15.4 \\
\hline $\mathrm{La}_{0.95} \mathrm{Ag}_{0.05} \mathrm{CoO}_{3}$ & SG & 456 & 46.9 & 45.0 & 35.9 & 11 \\
\hline $\mathrm{La}_{0.9} \mathrm{Ag}_{0.1} \mathrm{CoO}_{3}$ & FP & 480 & 32.9 & 22.5 & 21.3 & 11.6 \\
\hline $\mathrm{La}_{0.9} \mathrm{Ag}_{0.1} \mathrm{CoO}_{3}$ & SG & 482 & 33.2 & 22.7 & 25.8 & 7.4 \\
\hline $\mathrm{La}_{0.8} \mathrm{Ag}_{0.2} \mathrm{CoO}_{3}$ & $\mathrm{FP}$ & 435 & 58.6 & 47.3 & 40.6 & 18 \\
\hline $\mathrm{La}_{0.8} \mathrm{Ag}_{0.2} \mathrm{CoO}_{3}$ & SG & 480 & 36.6 & 17.2 & 16.7 & 19.9 \\
\hline $\mathrm{LaMnO}_{3}$ & FP & 435 & 59 & 54.1 & 49.9 & 9.1 \\
\hline $\mathrm{LaMnO}_{3}$ & SG & 583 & 7.5 & 4.0 & 2.0 & 5.5 \\
\hline $\mathrm{La}_{0.95} \mathrm{Ag}_{0.05} \mathrm{MnO}_{3}$ & FP & 427 & 66 & 60.5 & 58 & 8 \\
\hline $\mathrm{La}_{0.95} \mathrm{Ag}_{0.05} \mathrm{MnO}_{3}$ & $\mathrm{SG}$ & 479 & 36.3 & 27.5 & 17.0 & 19.3 \\
\hline $\mathrm{La}_{0.9} \mathrm{Ag}_{0.1} \mathrm{MnO}_{3}$ & FP & 395 & 84 & 82.0 & 75.0 & 9.0 \\
\hline $\mathrm{La}_{0.9} \mathrm{Ag}_{0.1} \mathrm{MnO}_{3}$ & SG & 464 & 43.6 & 30.1 & 22.1 & 21.5 \\
\hline $\mathrm{La}_{0.8} \mathrm{Ag}_{0.2} \mathrm{MnO}_{3}$ & $\mathrm{SG}$ & 535 & 15.4 & 15.0 & 14.0 & 1.4 \\
\hline
\end{tabular}


Fig. 1

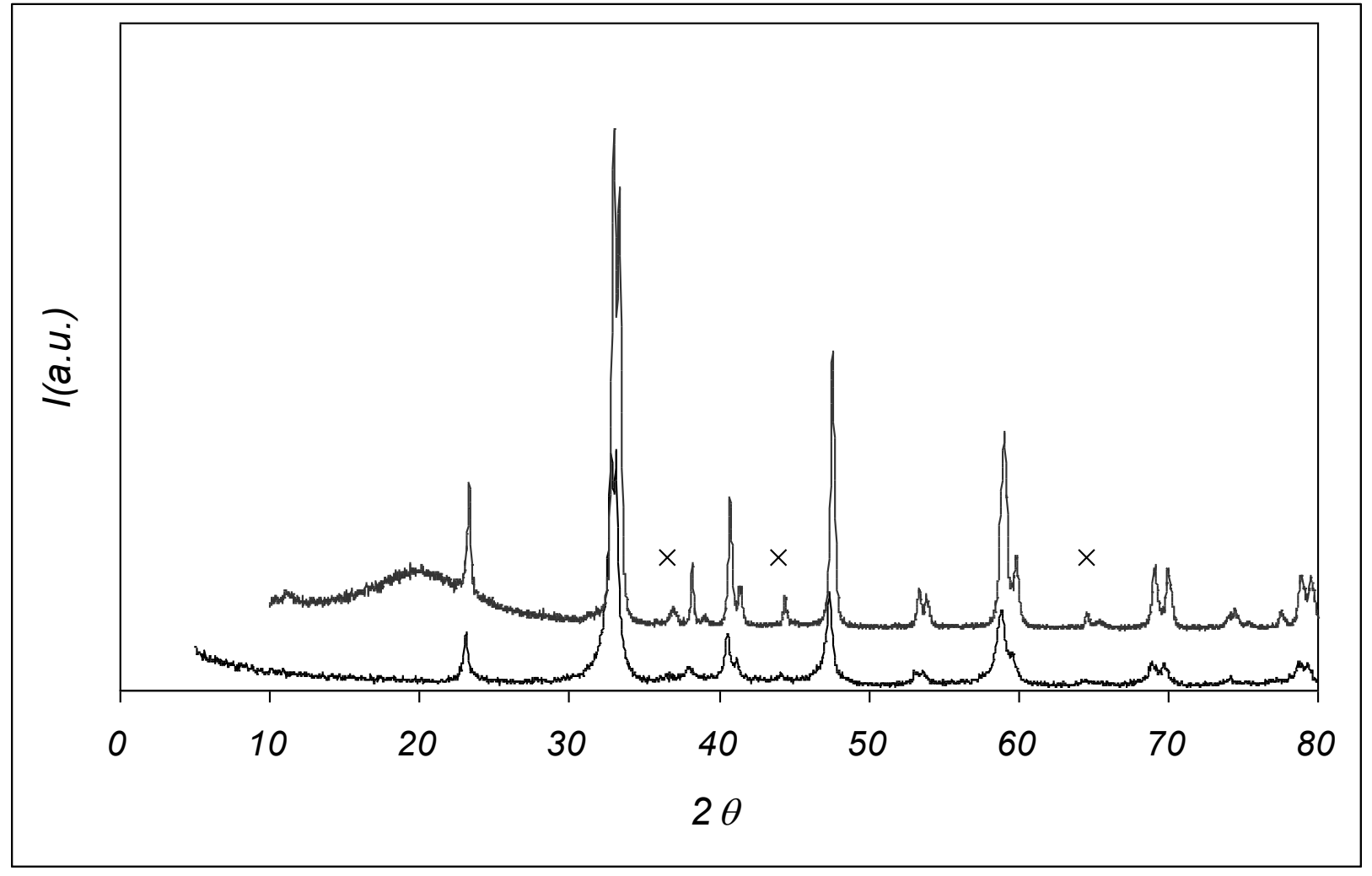

Fig. 2

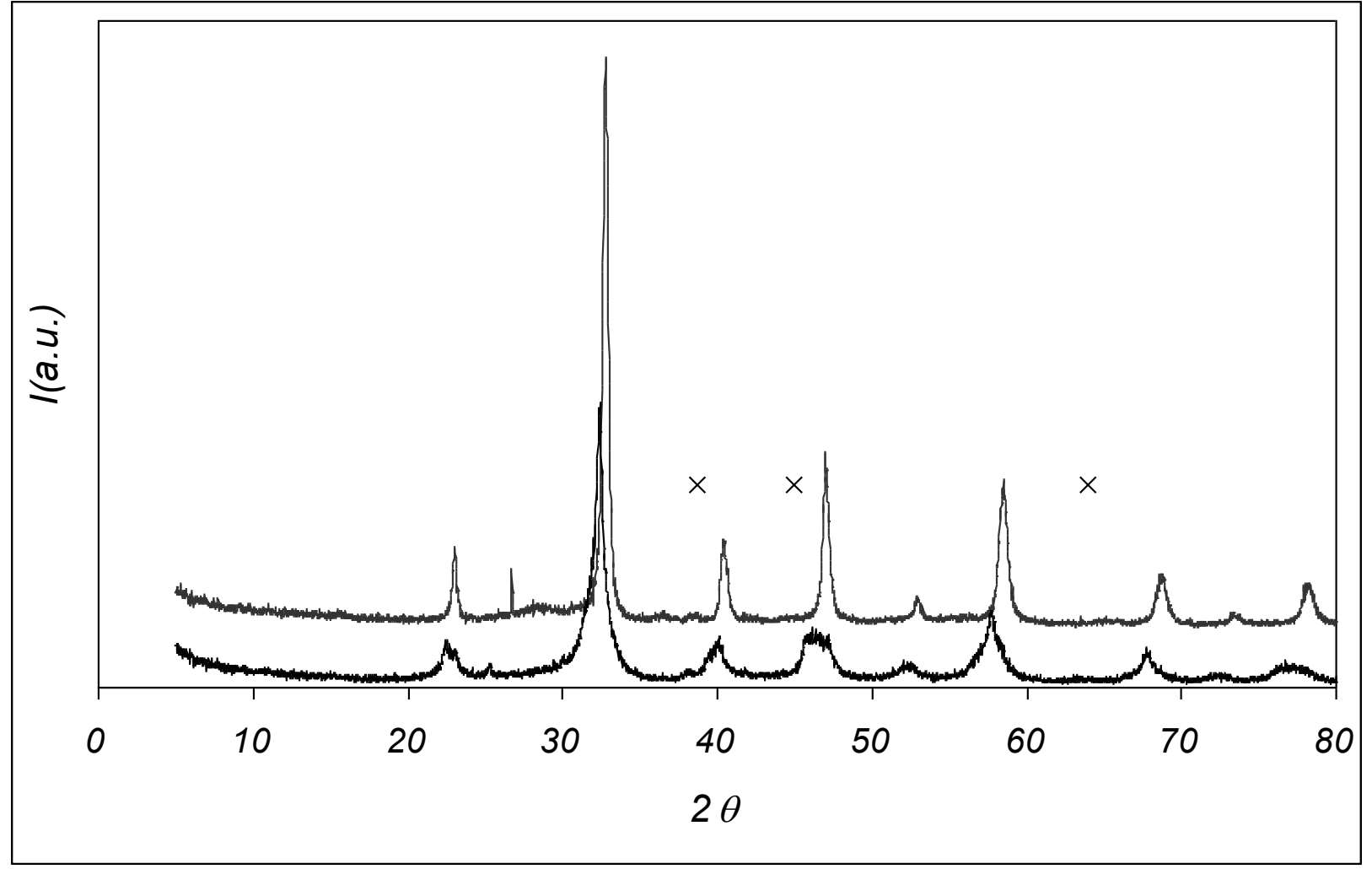


Fig. 3

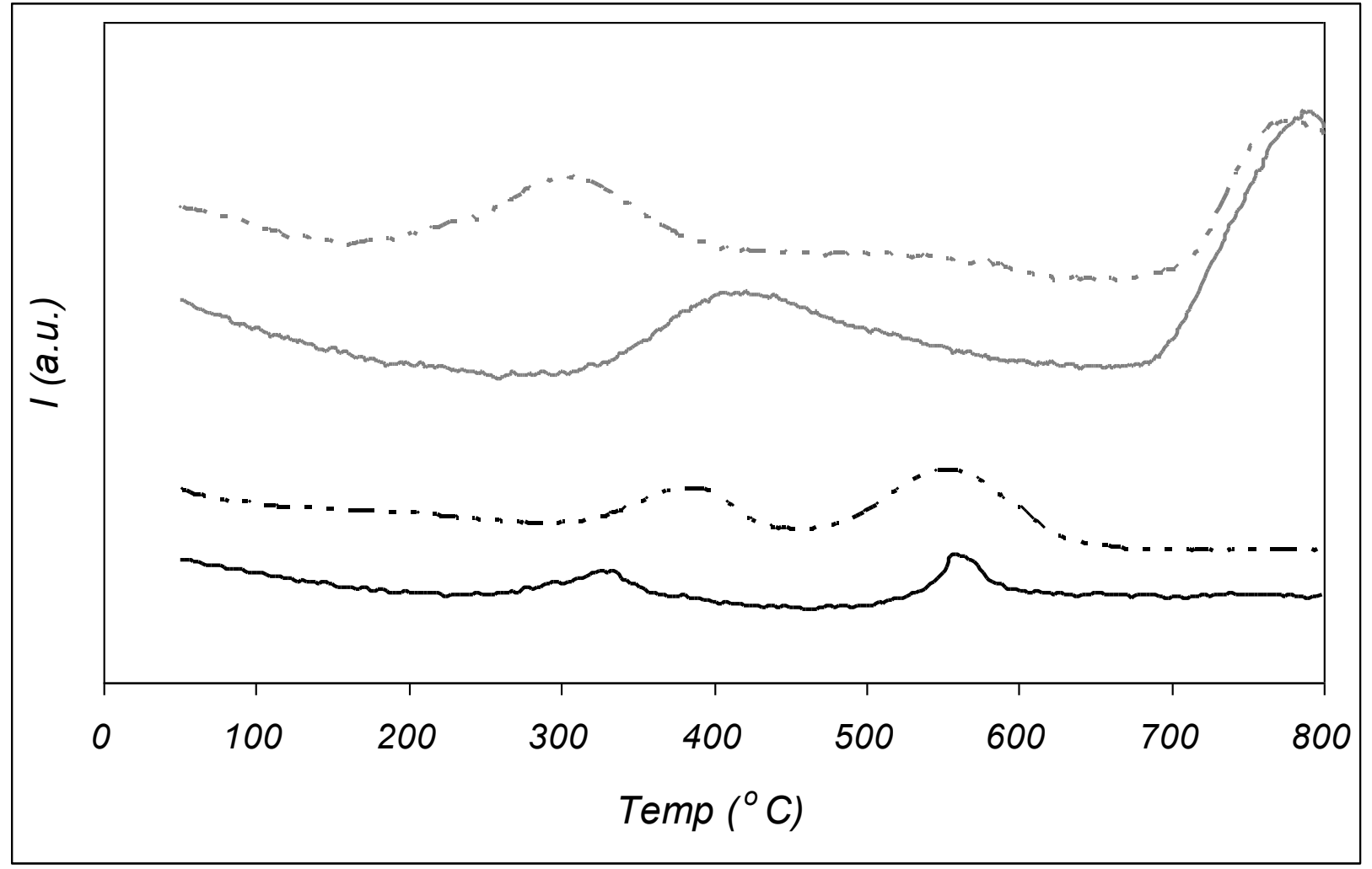

